\title{
THERMOPLASTIC VERSUS CONVENTIONAL HEAT CURED DENTURE BASES FOR IMPLANT - RETAINED MANDIBULAR OVERDENTURE
}

\author{
Raafat Hassan Riad", Ahmed Amin Moselhy** and Mahmoud Mohammed Alaswad ${ }^{* * *}$
}

\begin{abstract}
Objective: The aim of this study was to compare radiographically thermoplastic and conventional heat cured acrylic resin as denture base material for mandibular conventional type implant retained complete overdentures and evaluate the effect of this difference on the implants stability.
\end{abstract}

Materials and methods: Fourteen edentulous patients were selected to construct two implants retained mandibular overdenture. The patients were equally divided into two groups according to material of denture base: group I, patients with thermoplastic resin constructed by injection moulding technique; and group II, patients with denture bases constructed by conventional heat curing acrylic resin. Radiographic and implant stability parameters were evaluated 1 year study.

Results: There was no statistically significant difference between the thermoplastic and conventional heat cured denture bases for implant retained mandibular overdenture in bone resorption and stability of the implants.

Conclusion: There was no statistically significant difference between the thermoplastic and conventional heat cured implant overdenture bases. Both denture bases have beneficial effect on implant osseointegration and stability.

KEY WORD: edentulous mandible, overdenture, implants, thermoplastic resin.

\section{INTRODUCTION}

Edentulous patients often experience problems with their mandibular complete dentures. Lack of stability and retention of their mandibular denture, together with a decreased bite forces and altered masticatory functions are the main complaints of these patients. ${ }^{(1)}$

Conventional complete denture was the only treatment solution for the complete edentulism for long time. Nowadays, this is still the most

\footnotetext{
* Associate Professor, Military Medical Academy

** Lecturer, Prothodontics, Military Medical Academy

*** BDS, MSD Faculty of Dentistry, Suez Canal University (2011)
} 
considerably treatment, but there may be seen a growing directions towards using implants for fixed or removable restorations. Each treatment option has the risk of specific complications, dependent on their manufacturing particularities and biomechanical features. ${ }^{(2)}$

The concept of implant-supported overdentures nowadays can be considered as another proper solution for edentulism because of an increased awareness, the difference of clinical conditions, biomechanics and patients desires. ${ }^{(3)}$ The use of implants as a means of retention, support and stability of the denture has revolutionized the treatment concepts and should be made the treatment of choice, wherever possible. ${ }^{(4)}$ Conventional loading of mandibular two implant overdentures has been accepted as a "model for implant success".

The manner by which the implant overdenture attachment design distributes the forces determines the net effect on the supporting structure. The occlusal forces should better be directed with the longitudinal axis of the abutment to avoid producing excessive amount of torque. In response to functional stresses rearrangement of the bony trabecular pattern takes place, the change and remodeling of bone will vary according to the stresses applied. ${ }^{(5)}$

Stable levels of bone around dental implants are the key of successful outcome. Knowledge of the causative factors that affect alveolar resorption in the mandible is important to avoid the potentially severe consequences of residual ridge resorption in edentulous patients. ${ }^{(6)}$ There are many individual features that determine speed and extent of resorption such as age, sex and time elapsed since tooth extraction, osteoblast life span, local and systemic biochemical factors and physical factors, such as the pressure exerted on the bone by dentures. ${ }^{(7)}$ The radiography provides the most accurate means to evaluate the morphological features of the proposed fixture site, and evaluate the fixture after implantation. ${ }^{(8)}$
Implant stability has an important role in osseointegration, which was defined as a direct functional and structural interaction between the implant and surrounding bone..$^{(9,10)}$

Implant stability is obtained at two subsequent stages. Primary stability stage achieved from mechanical connection with cortical bone. It is influenced by the bone structure quality and quantity, surgical steps, diameter, length, and shape of the implant. (11) Secondary stability stage starts with regeneration and remodeling of the osseous tissue surrounding the implant after insertion. The time of implant loading with the prosthesis is based on the secondary stability. Therefore, it is very important to evaluate implant stability at several time points and to detect a long term prognosis. ${ }^{(10,12)}$

Walter Wright has provided the Poly methyl methacrylate (PMMA) as denture base material in 1937 , and it has become nearly the most commonly and standard material used to fabricate removable complete and partial dentures. In recent years, flexible polymers has been attracting attention as a denture base material because of a host of advantages: favorable aesthetic outcome, toxic safety to patients allergic to conventional metals and resin monomers, ${ }^{(13,14,17)}$ higher elasticity than conventional-polymerizing resins, sufficient strength for use as a denture base material, ${ }^{(18)}$ and use of heatmoulding instead of chemical polymerization to ease conventional challenges such as deformation during the polymerization process and the presence of non polymerized residual monomers, ${ }^{(19-21)}$ Furthermore, its advantageous characteristics such as higher elasticity and higher moulding precision than heat-polymerizing base resins decreases the stress on abutment teeth as well as facilitate denture retention by utilizing the undercuts of abutment teeth in the denture base design.

This study was concerned with the clinical performance of two denture base materials, thermoplastic and conventional heat cure acrylic 
and their effect on the stresses induced on the bone adjacent to the implant.

\section{MATERIALS AND METHODS}

Fourteen edentulous male patients at age of 55 to 65 years with conventional complete denture seeking implant-retained overdentures were selected using standardized inclusion and exclusion criteria. The patients were equally divided into two groups according to material of denture base (thermoplastic and conventional).

Two sharp incisions each is about $3 \mathrm{~cm}$ in length were made at reference points on the crest of ridge. After reflection of mucoperiosteum, two implants (ANKYLOS C ${ }^{\circledR}$, DENTSPLY, Germany) with smooth collar, $3.5 \mathrm{~mm}$ in diameter and $11 \mathrm{~mm}$ length were used following the instructions provided by manufacturer's surgical manual. Postoperative chlorohexidine mouthwash, antibiotics and analgesics were prescribed. Three months after fixture installation, the second surgical phase was performed. Snap (ball) attachment (ANKYLOS C ${ }^{\circledR}$, DENTSPLY) was inserted and threaded into the cover screw of the implant and tightened well.

Ten days after abutment connection, the prosthetic treatment was started. All patients received a new maxillary denture and an overdenture for mandibular jaw. The first group

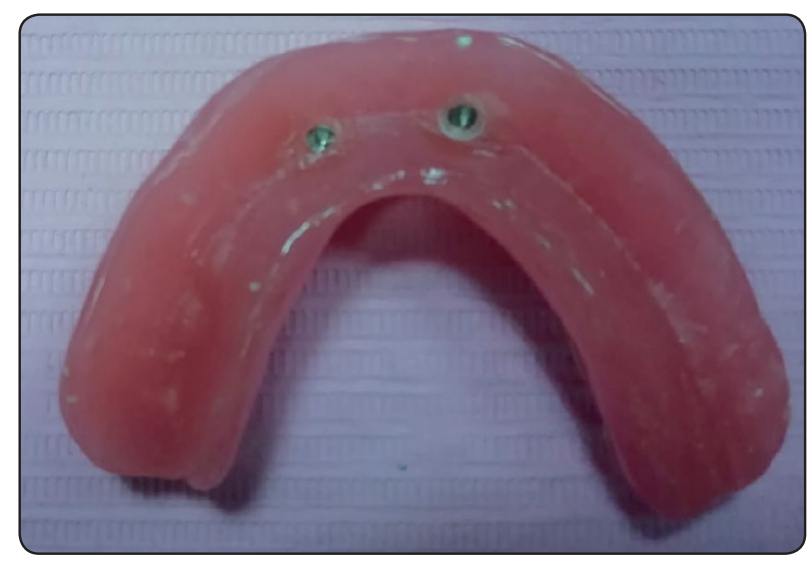

IMAGE (1) received overdenture constructed by injection moulding technique of thermoplastic resin (Sabilex Acrilfast, Argentina), the second group received overdenture constructed by heat cure acrylic resin with conventional technique (Vertex Dental, Netherlands)

\section{Picture overdenture}

Marginal bone height changes around the implants were evaluated at time of implant loading, 6 and 12 months using cone beam computed tomography (CBCT). Implant stability was measured by means of resonance frequency measurement (Osstell ISQ) using the respective Smartpeg abutment according to the manufacturer's recommendations at implant insertion and 12 months after loading.

All data was collected, tabulated and statistically analyzed. Numerical data were explored for normality by checking the data distribution, calculating the mean and median values, evaluating histograms and normality curves and using Kolmogorov-Smirnov and Shapiro-Wilk tests.

Data was presented by mean and standard deviation. $\mathrm{T}$ test was used for comparison between the two groups. Paired t test was used for comparison between follow up interval. The significance level was set at $\mathrm{P} \leq 0.05$. Statistical analysis was performed with IBM ${ }^{\circledR}$ SPSS ${ }^{\circledR}$ Statistics Version 20 for Windows.

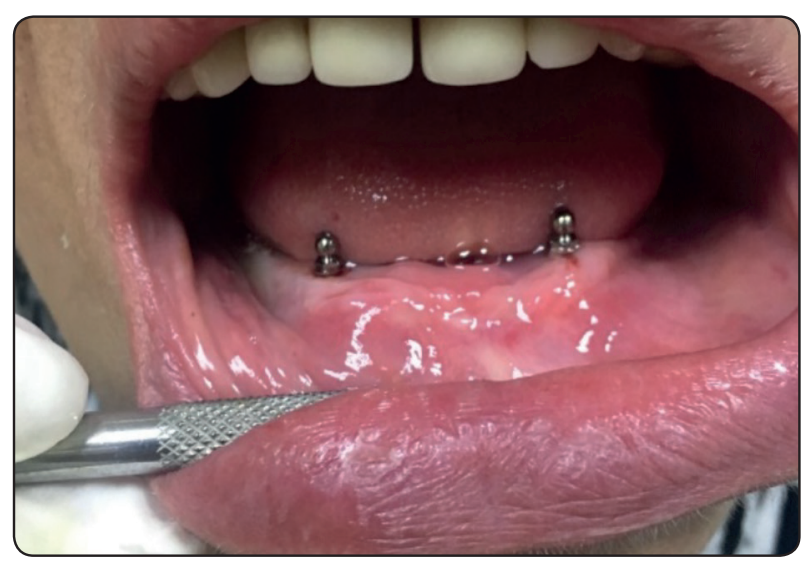

IMAGE (2) 


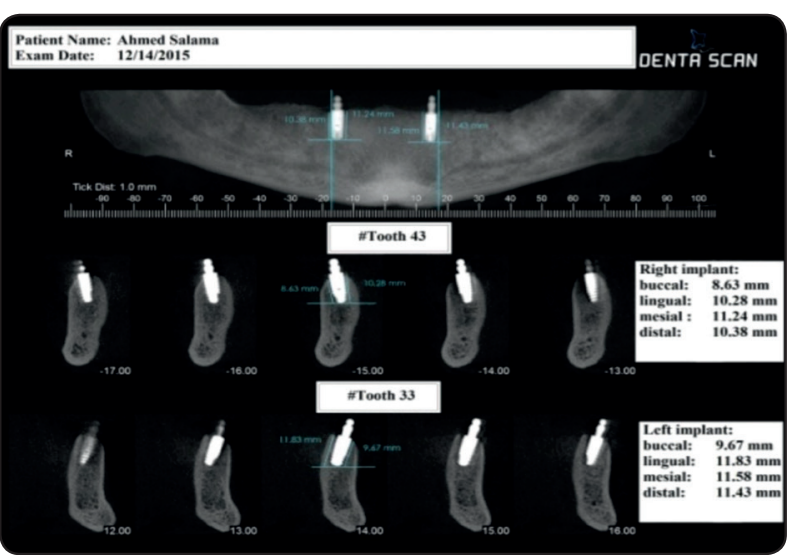

IMAGE (3)

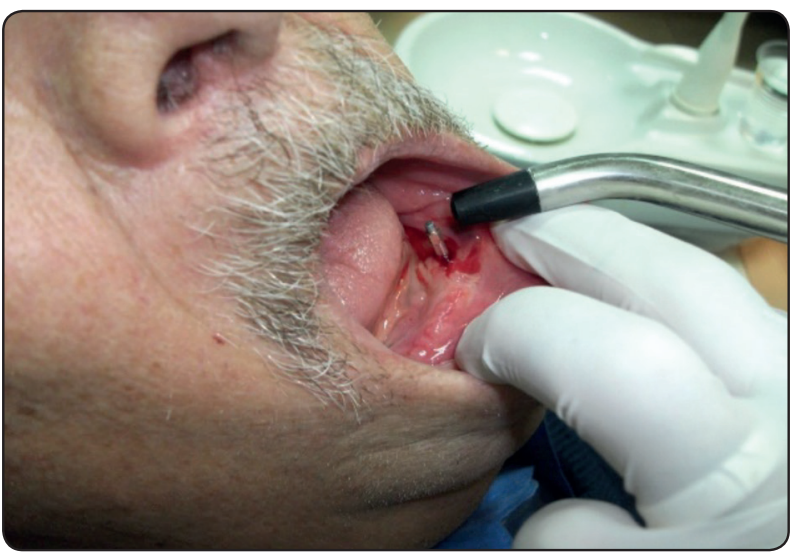

IMAGE (5)

\section{RESULTS}

The study was performed on fourteen male patients which were divided normally into two equal groups according the type of ovedenture base material.

Kolmogorov-Smirnov and Shapiro-Wilk tests were used to assess data normality and data was assessed normally distributed.

Paired $\mathrm{t}$ test was used for comparison between amount of bone height changes and implants stability records that occurred in two follow up intervals (baseline to 6 months and 6 to 12 months) in each group

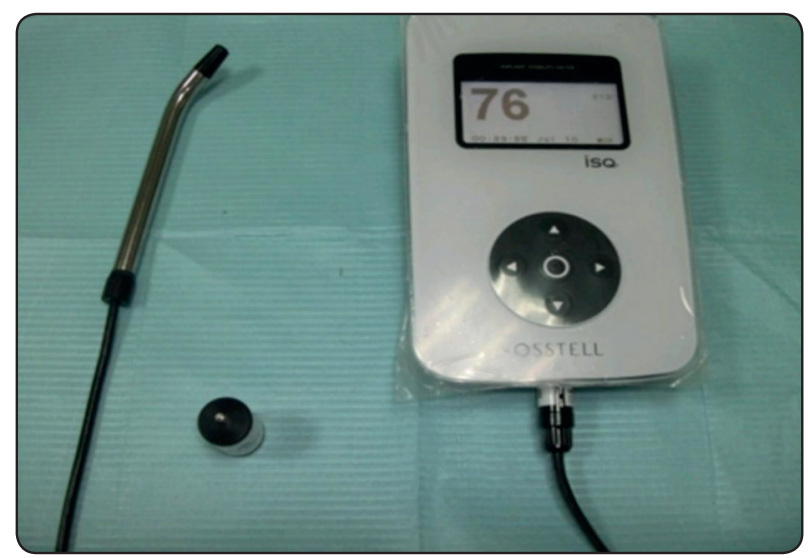

IMAGE (4)

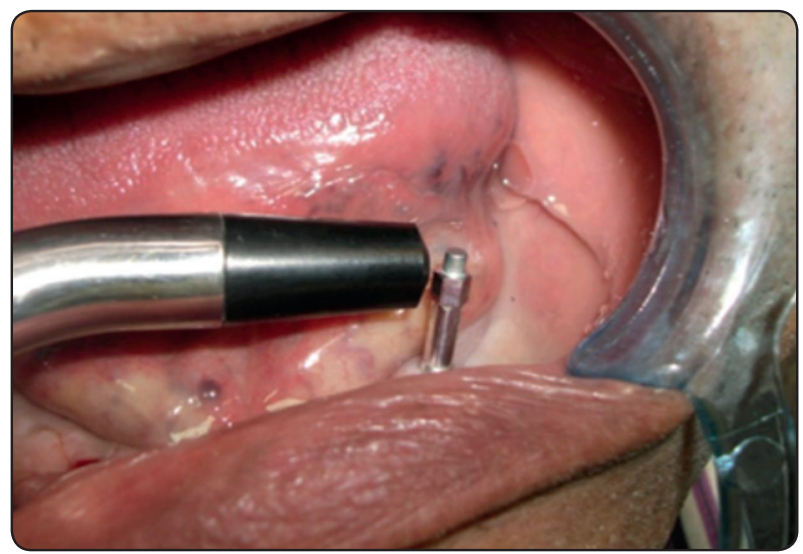

IMAGE (6)

Radiographic evaluations (bone height in $\mathbf{m m}$ ):

\section{A: Buccal aspect of implants:}

The mean value for the amount of bone loss for group I on buccal aspect of implants from 0 to 6 month was 1.4788 and the mean value for the amount of bone loss in group II was 1.4463 , the mean value for the amount of bone loss for group I on buccal aspect of implants from 6 to 12 month was 0.4075 and the mean value for the amount of bone loss in group II was 0.4488 , The mean value for the amount of bone loss for group I on buccal aspect of implants from 0 to 12 month was 1.8863 . While the mean value for the amount of bone loss in group II was 1.8950 , there was a decrease in bone height in both groups throughout the follow up intervals. Group II showed higher value and difference was statically not significant. (Table 1) 
The mean value for the amount of bone loss for group I on lingual aspect of implants from 0 to 6 month was 0.3688 and the mean value for the amount of bone loss in group II was 0.3525 ,the mean value for the amount of bone loss for group I on lingual aspect of implants from 6 to 12 month was 0.3638 and the mean value for the amount of bone loss in group II was 0.3400 ,group I showed higher value and difference was statically not significant.
The mean value for the amount of bone loss for group I on lingual aspect of implants from 0 to 12 month was 0.7325 . While the mean value for the amount of bone loss in group II was 0.6925 ,there was a decrease in bone height in both groups throughout the follow up intervals, group I showed higher value and difference was statically not significant. Table(2)

TABLE (1) T test comparing the mean values for the amount of bone loss at buccal aspect of implants:

\begin{tabular}{|c|c|c|c|c|}
\hline Buccal & & Mean & Std. Deviation & $\mathrm{P}$ value \\
\hline \multirow{2}{*}{ 0-6 months } & Thermoplastic Base (group I) & 1.4788 & 0.79208 & \multirow{2}{*}{0.926} \\
\hline & Conventional Base (group II) & 1.4463 & 0.56447 & \\
\hline \multirow{2}{*}{ 6-12 months } & Thermoplastic Base (group I) & 0.4075 & 0.44698 & \multirow{2}{*}{0.849} \\
\hline & Conventional Base (group II) & 0.4488 & 0.40215 & \\
\hline \multirow{2}{*}{$0-12$ months } & Thermoplastic Base (group I) & 1.8863 & 0.89594 & \multirow{2}{*}{0.982} \\
\hline & Conventional Base (group II) & 1.8950 & 0.58153 & \\
\hline
\end{tabular}

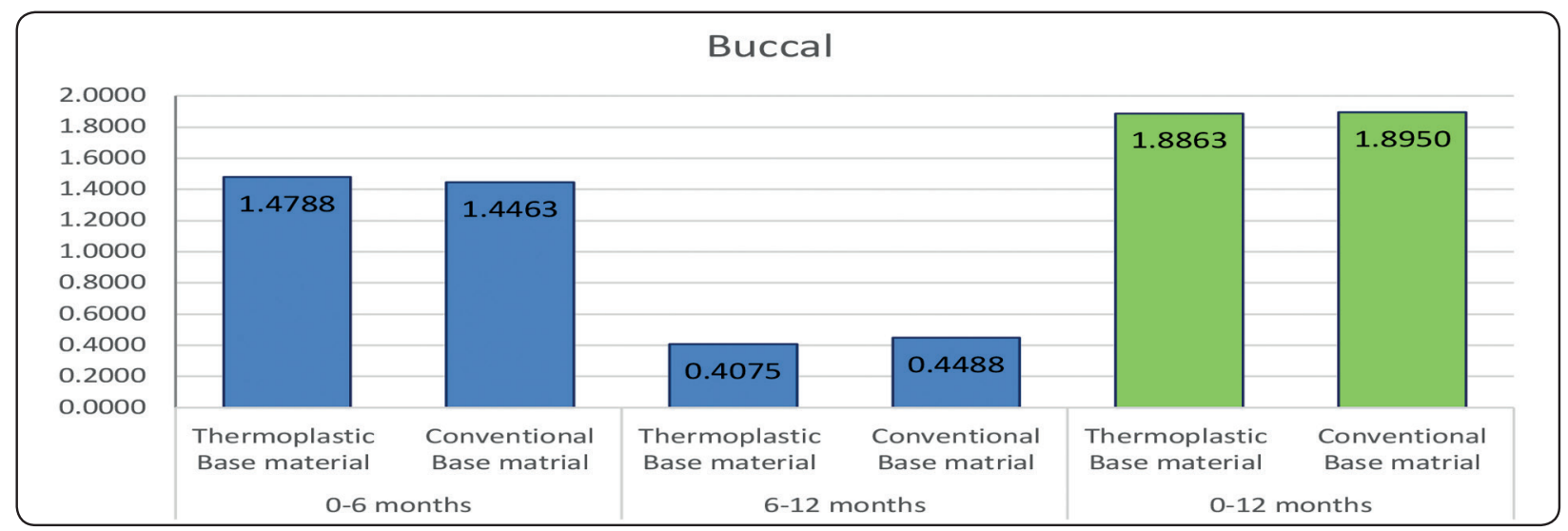

Fig (1): The mean values for the amount of bone loss at buccal aspect of implants.

TABLE (2) T test comparing the mean values for the amount of bone loss at lingual aspect of implants:

\begin{tabular}{|c|l|l|l|c|}
\hline Lingual & & Mean & Std. Deviation & P value \\
\hline \multirow{2}{*}{ 0-6 months } & Thermoplastic Base (group I) & 0.3688 & 0.17275 & \multirow{2}{*}{0.874} \\
\cline { 2 - 5 } & Conventional Base (group II) & 0.3525 & 0.22582 & \multirow{2}{*}{0.868} \\
\hline \multirow{2}{*}{ 6-12 months } & Thermoplastic Base (group I) & 0.3638 & 0.25478 & \\
\cline { 2 - 5 } & Conventional Base (group II) & 0.3400 & 0.30543 & \multirow{2}{*}{0.824} \\
\hline \multirow{2}{*}{ 0-12 months } & Thermoplastic Base (group I) & 0.7325 & 0.31235 & 0.38917 \\
\cline { 2 - 5 } & Conventional Base (group II) & 0.6925 & & \\
\hline
\end{tabular}




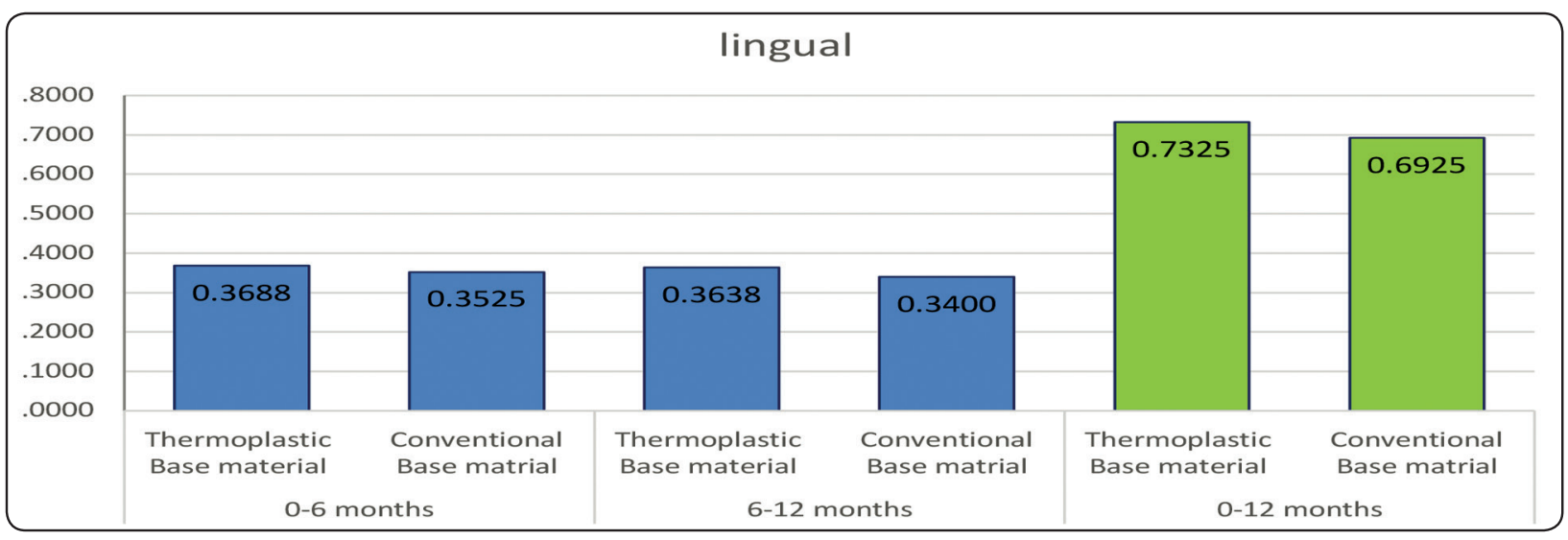

Fig (2): The mean values for the amount of bone loss at lingual aspect of implants

\section{DISCUSSION}

As success of implant is multi-factorial, the stresses transmitted through the denture base of implant retained overdenture were the domain of the present study.

The changes in the supporting structures surrounding the implants are most probably due to several factors, including; biological and mechanical factors related to the load applied to the implants from the denture. On the other hand, the surgical procedures during implant installment initiate bone resorption. ${ }^{(22)}$

Successful osseointegration of dental implants for both groups were assessed through two different methods, cone beam radiograph and implant stability device. Changes in marginal bone levels over time are considered to be an important parameter for the evaluation of implant success in long-term studies. ${ }^{(8)}$

The mean value for amount of bone loss around the implants was 0.87 to $1.03 \mathrm{~mm}$. This is in agreement with previous studies which found out that there was average bone height loss of $0.9-1.6$ $\mathrm{mm}$ through the first year, then subsequent bone loss less than $0.2 \mathrm{~mm}$ was recorded during the follow up period. ${ }^{(23)}$

Moreover, crestal bone loss around implants supporting overdentures appears to be affected by factors such as location, attachment system, number of implants supporting the overdenture and also bending effect of thermoplastic material. ${ }^{(24)}$

The thermoplastic denture base (group I) showed slightly decrease in the amount of bone loss in relation to conventional denture base (group II) throughout the follow up intervals. The high resiliency of thermoplastic denture base allows a higher standard of function to balance masticatory forces over entire supporting ridge instead of individual support points. As a result, the balanced stress distribution lead to decrease the forces directed to the implants and consequently to the alveolar bones. ${ }^{(25)}$

The stress on ridge under PMMA denture was equally distributed on occlusal, lingual and buccal surfaces. However, the stress under the thermoplastic denture was concentrated on the top of surface of residual ridge where the flexibility of thermoplastic type absorbs the stress directed to buccal and lingual surfaces of denture. ${ }^{(26)}$

The comparison between the mechanical properties of a polyamide-based denture material, injection-molded PMMA base material and a conventional compression molded PMMA. The results showed that the polyamide flexural strength was not significantly different from compressionmolded PMMA and that the flexural modulus of 
polyamide was lower than compression-molded PMMA material. (27) This is in agreement with present study results that showed slightly decrease in the amount of bone loss in thermoplastic group relation to conventional group and it was statistically not significant.

Primary and secondary implant stability recorded after insertion is regarded as critical sign for success of the implant with time. (28) In the present study, initial ISQ mean values of 59 to 60.5 for both groups were recorded. The obtained stability reduction corresponds with bone remodeling stage. ${ }^{(29)}$ The values of 71 for group I and 68 group II were obtained at second stage surgery. The results of present study were supported by previous studies which reported ISQ values of $69-75.5$ for successfully integrated implant following one year of loading. ${ }^{(30)}$

Although the mean values of implants stability support that the thermoplastic dentures have proper distribution of stresses in comparison to conventional type acrylic dentures, no significant statistical differences in terms of primary and secondary implant stability were observed between both groups.

The results of this study was found to be in agreement with other studies which reported that thermoplastic flexible denture has higher values in case of tensile, compressive, shear and stress transmitted to the abutment which could be explained through the fact that thermoplastic denture base directly transmit the stresses to the underlying structure. ${ }^{(31)}$

\section{CONCLUSION}

- There was no statistically significant difference between the thermoplastic and conventional heat cured denture bases for implant retained mandibular overdenture.

- Both denture bases have beneficial effect on implant osseointegration and stability.

\section{REFERENCES}

1. Emami E, de Souza RF, Kabawat M, Feine JS; The impact of edentulism on oral and general health. Int J Dent DOI:10.1155/2013/498305, 2013.

2. Derek D'Souza; Residual ridge resorption. Oral Health Care - Prosthodontics, Periodontology, Biology, Research and Systemic Conditions, Prof. Mandeep Virdi (Ed.), 978953-51- 0040-9, 2012.

3. Naert I, Gizani S, Vuylsteke M and Van Steenberghe D; A 5-year prospective randomized clinical trial on the influence of splinted and unsplinted oral implants retaining a mandibular overdenture: prosthetic aspects and patient satisfaction. J Oral Rehab 26: 195-203, 1999.

4. American College of Prosthodontists (ACP); The prosthodontic diagnostic index for complete edentulism (PDI-CE) http://www.gotoapro.org/assets/1/7/ Complete_ Edentulism_Checklist.pdf accesed 1 September, 2014.

5. Porter JA, Petropoulos VC and Brunski JB; Comparison of load distribution for implant overdenture attachment. Int J Oral Maxillofac Implants 17: 651-659, 2002.

6. Atwood DA; Some clinical factors related to rate of resorption of residual ridges. J Prosthet Dent 86:119-25, 2001.

7. Spiechowicz E; Prosthodontics. Medical Publishing PZWL, Warszawa, 1998.

8. Mauriello S.M. and Platin E.: Dental digital radiographic imaging. J Dent Hyg 75(4):323-31.2001.

9. Branemark P, Hansson B, Adell R, Breine U, Lindstrom $\mathrm{J}$, Hallen $\mathrm{O}$ and Ohman, A; Osseointegrated implants in the treatment of the edentulous jaw. Experience from a 10year period. Scandinavian J Plast Reconstr Surg 16: 1-132, 1977.

10. Sennerby L and Roos J; Surgical determinants of clinical success of osseointegrated oral implants: A review of the literature. Int J prosthodont 11: 408-420, 1998.

11. Meredith N; Assessment of implant stability as a prognostic determinant. Int J prosthodont 11: 491-501, 1998.

12. Atsumi M,Park S H and Wang H L; Methods used to assess implant stability: Current status. Int J Oral Maxillofac Implants 22: 743-754, 2007.

13. RK Alla, Suresh Sajjan MC, Ramaraju AV, Ginjupalli $\mathrm{K}$ and Upadhya $\mathrm{N}$; Influence of fiber reinforcement on the properties of denture base Resins, J Biomater Nano Biotech 4(1):91-97, 2013. 
14. Hargreaves AS; Nylon as a denture base material. Dent Pract Dent Rec 22 :122-8, 1971.

15. Stafford GD, Huggett R, MacGregor AR and Graham J; The use of nylon as a denture-base material. J Dent 14: 18-22, 1986.

16. Parvizi A, Lindquist T, Schneider R, Williamson D, Boyer $\mathrm{D}$ and Dawson DV; Comparison of the dimensional accuracy of injection-molded denture base materials to that of conventional pressure-pack acrylic resin. J Prosthodont 13: 83-89, 2004.

17. Yunus N, Rashid AA, Azmi LL and Abu-Hassan MI; Some flexural properties of a nylon denture base polymer. J Oral Rehabil 2005; 32: 65-71.

18. Katsumata $\mathrm{Y}$, Hojo S, Ino S, Hamano N, Watanabe T, Suzuki Y, Ikeya H, Morino T and Toyoda M; Mechanical characterization of a flexible nylon denture base material. Bull Kanagawa Dent Col 35: 177-82, 2007.

19. Deguchi R; Polyamide 6. Japan Plastics 41: 35- 41, 1990.

20. Kometani K and Suyama T; Polyamide 11, 12, 610. Japan Plastics 41: 42-8, 1990.

21. Katsumata Y, Hojo S, Hamano N, Watanabe T, Yamaguchi $\mathrm{H}$ andOkada $\mathrm{S}$; Bonding strength of autopolymerizing resin to nylon denture base polymer. Dent Mater J 28: 409418, 2009.

22. Oshida Y, Tuna EB, Aktören O and Gençay K; Dental implant systems. Int. J. Mol. Sci. 11, 1580-1678, 2010.

23. Weber HE, Buser D, Fiorellini JP and Williams RC; Radiographic evaluation of crestal bone levels adjacent to non-submerged titanium implants. Clin Oral Impl Res. 3: 181-8, 1992.
24. Hatch JP, Shinkai RSA, Sakai S, Rugh JD and Paunovich ED; Determinants of masticatory performance in dentate adults. Archives of Oral Biology 46: 641-48; 2000.

25. Arda $\mathrm{T}$ and Arikan A; An in vitro comparison of retentive force and deformation of acetal resin and cobalt-chromium clasps. J Prosthet Dent 94: 267-74, 2005.

26. Mehta K, Shetty O and Ram S; A Comparative evaluation of the stress distribution under polymethyl methacrylate acrylic aesin and acetyl acrylate resin dentures during occlusal loading: An in vitro heal talk. 05:02, 2012.

27. Ucar Y, Akova T and Aysan I; Mechanical properties of polyamide versus different PMMA denture base materials. J Prosthodont. 21: 173-176, 2012.

28. Östman PO, Hellman M and Sennerby L; Direct implant loading in the edentulous maxilla using a bone densityadapted surgical protocol and primary implant stability criteria for inclusion. Clin Implant Dent Relat Res. 7 Suppl 1:560-9, 2005.

29. Boronat-Lopez A, Balaguer-Martinez J, Lamas- Pelayo J, Carrillo Garcia C and Penarrocha Diago M; Resonance frequency analysis of dental implant stability during the healing period. Med Oral Patol Cir Bucal 13(4):244-247, 2008 .

30. Simunek A, Kopecka D, Brazda T, Strnad J, Capek L and Slezak R; Development of implant stability during early healing of immediately loaded implants. Int J Oral Maxillofac Implants 27:619-627, 2012.

31. Mohamed A. Abd El Kader; Comparison between two different denture base materials, finite element analysis; Cairo University, 2002. 